\title{
A Study on Cardiopulmonary Function Tests in Thalassemia Major Patients (6-14 Years) and its Correlation to Serum Ferritin
}

\author{
Pawan Nandurkar*, Manjusha Goel and Shweta Sharma
}

Department of Pediatrics, Gandhi Medical College, Bhopal, India

\begin{abstract}
Background: Patients with thalassemia major require regular blood transfusions which causes iron overload which untreated leads to respiratory, cardiac, hepatic and endocrine dysfunction.

Objectives: This study was undertaken to assess cardiopulmonary functions in thalassemia major patients and its correlation to serum ferritin.

Methods: A hospital based observational study was conducted over a period of 11 months, between November 2015 and September 2016. 47 thalassemia major patients were included along with 20 age and sex matched controls were taken as controls.

Results: Mean age in our study population was $9.44 \pm 2.030$ years. The mean Sr. ferritin level was $3217+1351.853$ ng/dl. $18(38 \%)$ patients had low FEV1 and FVC; suggesting restrictive pattern along with small airway obstruction suggested by reduced FEF $25 \%$ to $75 \%$. We observed that as the serum ferritin level increased, mean value of FEV1, FVC, FEV1/FVC, FEF (25\% to $75 \%)$ decreased and it was statistically significant in cases with ferritin $>3000 \mathrm{ng} / \mathrm{ml}$ ( $p$ value $<0.05$ ). In echocardiography interventricular septal thickness and posterior wall diameter were significantly increased in thalassemia patients as compared to controls. The mean value of EF was lower among cases than in controls and this decrease in EF was statistically significant $(p<0.05)$ but there was no systolic dysfunction. 16 patients out of $23(69 \%)$ had dilated cardiomypathy in group where sr ferritin was $>3000 \mathrm{ng} / \mathrm{dl}$ and 5 patients out of $17(31 \%)$ had dilated cardiomypathy in ferritin levels of 2000 to $3000 \mathrm{ng} / \mathrm{dl}$. So the cardiovascular complications were found to be higher in the high-ferritin group (serum ferritin>3000 ng/dl) than in low-ferritin group (serum ferritin 1000-2000). In our study among 47 Thalassemic patients, $15(40 \%)$ were found to have both cardiac pathology as well as pulmonary dysfunction. This finding was statistically significant.
\end{abstract}

Conclusion: At the end of our study on thalassemic patients, we concluded that all the PFT parameters were decreased with increasing Sr. ferritin level. Most of the echocardiographic parameters were found to be significantly deranged with reference to increase in Sr. ferritin levels. Nearly half of the patients were found to have both pulmonary and cardiac involvement.

Keywords: Thalassemia; Spirometry; Echocardiography; Ferritin

\section{Introduction}

Thalassemia is a common cause of chronic haemolytic anaemia in India. It was first described by Thomas B Colley in 1925 and was called Colley's anaemia. Deficiency of alpha chain is known as alpha thalassemia and of beta chain is called beta thalassemia. Thalassemia is the most common monogenetic disorder worldwide. The disease is transmitted by autosomal recessive manner.

Thalassemia is a major health problem, placing an emotional, psychological and economic burden on millions of people around the World. Recent data indicates that about $3 \%$ of the World's population is a carrier of beta thalassemia [1]. 3,00,000 to 5,00,000 children are born each year worldwide with the severe homozygous state of this disease. Repeated blood transfusion in thalassemia patients leads to iron overload which causes respiratory, cardiac, hepatic and endocrine dysfunction. Tissue iron overload can be measured by Magnetic Resonance Imaging or by Serum ferritin level. Though imaging is more specific for assay of tissue iron overload, ferritin assay is preferred as it is easy to perform and cost effective.

Iron overload leading to pulmonary damage is seen in many studies done worldwide, although most of these studies are done in adult patients. Studies have shown mostly restrictive lung disease in thalassemia patients but pathophysiology is not clearly established.

Cardiac failure due to iron overload remains the most common cause of death in patients with beta-thalassemia major, accounting for up to $71 \%$ of all deaths from this disease [2,3]. Cardiac complications are related to left ventricular dysfunction leading to gradual cardiac failure and cardiogenic death. Echocardiography is a noninvasive technique that evaluates cardiac anatomy and function with images and recordings produced by sound energy. It has an established role in the assessment of left ventricular structure and performance [4].

Study was undertaken to assess the effect of iron overload on pulmonary and cardiac functions.

\section{Materials and Method}

A hospital based observational study was conducted in the Department of Pediatrics, Gandhi Medical College, Bhopal over a period of 11 months, between November 2015 and September 2016. Study population was diagnosed case thalassemia major patients confirmed by electrophoresis in the age group 6 to 14 years. Along with this 20, age and sex matched controls were taken. Exclusion criterias are

${ }^{*}$ Corresponding author: Pawan Nandurkar, Department of Pediatrics, Gandh Medical College, Bhopal, India, Tel: 0755-2540590; E-mail: pawannandurkar@yahoo.com

Received March 02, 2018; Accepted March 15, 2018; Published March 22, 2018

Citation: Nandurkar P, Goel M, Sharma S (2018) A Study on Cardiopulmonary Function Tests in Thalassemia Major Patients (6-14 Years) and its Correlation to Serum Ferritin. J Pulm Respir Med 8: 450. doi: 10.4172/2161-105X.1000450

Copyright: (c) 2018 Nandurkar P, et al. This is an open-access article distributed under the terms of the Creative Commons Attribution License, which permits unrestricted use, distribution, and reproduction in any medium, provided the original author and source are credited. 
Citation: Nandurkar P, Goel M, Sharma S (2018) A Study on Cardiopulmonary Function Tests in Thalassemia Major Patients (6-14 Years) and its Correlation to Serum Ferritin. J Pulm Respir Med 8: 450. doi: 10.4172/2161-105X.1000450

Page 2 of 4

1. Thalassemic children with co-existing cardiac or respiratory disease.

2. Age less than 6 years and more than 14 years

3. Thalassemia patients admitted with severe illness.

4. Patients having congenital defects like cleft lip and palate or neuromuscular disorder as they are unable to perform spirometry maneuvers.

Study variables were age, serum ferritin, pulmonary function test parameters studied were $\mathrm{FEV}_{1}, \mathrm{FVC}, \mathrm{FEV}_{1} / \mathrm{FVC}, \mathrm{FEF} 25 \%$ to $75 \%$, Echocardigraphic parameters-left ventricular diameter end systolic (LVDs), left ventricular diameter end diastole (LVDd), posterior wall thickness (PWT), inerventricular septal thickness (IVST) and left ventricular ejection fraction (LVEF).

47 children were included in the study. Detailed history was taken in all children with thalassemia major. Thorough physical examination was done to find out any pre-existing cardiac or respiratory disease. Patients who fulfilled inclusion criteria were included in the study after obtaining written informed consent from the parents or legal guardians. Detailed history was taken regarding frequency of blood transfusion and chelation therapy. History of breathlessness or any symptoms of respiratory system illness was specifically asked. Sr. ferritin of all the cases were done and recorded at the time of study and then they were taken for spirometry.

Spirometry was done using windows based digital Spirometer, RMS helios spirometer. Procedure of spirometry was explained and demonstrated to the subjects properly. All patients were advised to do the procedure 3 times and best of these 3 scores was taken. American Thoracic Society (ATS) criteria for acceptability and repeatability of spirometry were strictly followed [5]. All measurements and history was documented in a pre-structured proforma. Echocardiography was also done in all these patients. Echocardiographic images were obtained by Philips HD-11 Digital Ultrasound Machine with 4 different standard transducer positions the parasternal, the apical, the suprasternal, and the subcostal one. Conventional echocardiographic measurements were done according to the American Society of Echocardiography guidelines.

\section{Statistical Analysis}

In present study continuous variables were presented as mean. Mann whitney test was applied as data followed normative distribution. Nominal categorical data between the groups were compared using Chi-square test or Fischer extract test as appropriate. $\mathrm{P}<0.05$ was taken to indicate statistically significant difference. Multivariate regression analysis was done for analyzing multiple categorical variants using SPSS version 15 (Tables 1-4).

\section{Results}

In this study 47 patients of thalassemia major were included; out of which 35 were male and 12 female. In control group, we had total sample size of 20 healthy children, out of which 13 were male and 7

\begin{tabular}{|c|c|c|c|c|}
\hline Variables & Mean & Standard Deviation & N & P values \\
\hline 6-8 Years & 2160.38 & 875.92 & 16 & 0.001 \\
\hline 9-10 Years & 3232.33 & 798.49 & 15 & 0.96 \\
\hline 11-12 Years & 4058.57 & 1347.26 & 14 & 0.045 \\
\hline 13-14 Years & 5682.5 & 307.59 & 2 & 0 \\
\hline${ }^{*}$ Compared with group mean with Mann Whitney Test \\
\hline
\end{tabular}

Table 1: Mean ferritin level $(\mathrm{Ng} / \mathrm{DI})$ in different age.

\begin{tabular}{|c|c|c|c|c|c|}
\hline FERRITIN (mg/dI) & & FEV $_{\mathbf{1}}$ & FVC & FEV $_{\mathbf{1}} /$ FVC & FEF25-75 \\
\hline & MEAN & 91.375 & 93.5125 & 97.375 & 86.6625 \\
\cline { 2 - 6 } & SD & 4.95861 & 4.38029 & 2.29643 & 5.26767 \\
\cline { 2 - 6 } & $\mathrm{N}$ & 8 & 8 & 8 & 8 \\
\cline { 2 - 6 } & P Value & 0 & 0 & 0.609 & 0.009 \\
\hline \multirow{3}{*}{$2000-3000$} & MEAN & 86.9063 & 88.4938 & 97.9375 & 83.175 \\
\cline { 2 - 6 } & SD & 5.48142 & 4.59543 & 2.73468 & 5.42482 \\
\cline { 2 - 6 } & N & 16 & 16 & 16 & 16 \\
\cline { 2 - 6 } & P Value & 0.057 & 0.045 & 0.229 & 0.196 \\
\hline \multirow{3}{*}{$>3000$} & MEAN & 78.3087 & 80.2609 & 96.05 & 77.58 \\
\cline { 2 - 6 } & SD & 6.14484 & 5.35798 & 4.62702 & 5.20214 \\
\cline { 2 - 6 } & N & 23 & 23 & 23 & 23 \\
\cline { 2 - 6 } & P Value & 0.004 & 0.002 & 0 & 0.018 \\
\hline
\end{tabular}

${ }^{*}$ Compared with group mean with Mann Whitney Test

Table 2: Mean values of fev1, fvc, fev $1 / \mathrm{fvc}$ and fef $25 \%-75 \%$ in percentage of predicted value at different ferritin levels $(\mathrm{Ng} / \mathrm{Ml})$.

\begin{tabular}{|c|c|c|c|c|c|c|}
\hline Variables & & LVDd & LVDs & IVST & PWT & LVEF \\
\hline \multirow{3}{*}{$1000-2000$} & MEAN & 32.5375 & 21.8875 & 5.7875 & 5.3875 & 60 \\
\cline { 2 - 7 } & SD & 3.16947 & 3.46263 & 0.68752 & 0.70191 & 0 \\
\cline { 2 - 7 } & $\mathrm{N}$ & 8 & 8 & 8 & 8 & 8 \\
\cline { 2 - 7 } & P values & 0 & 0.018 & 0.92 & 0.788 & 0.039 \\
\hline \multirow{3}{*}{$2000-3000$} & MEAN & 40.4438 & 25.6188 & 6.8375 & 6.4563 & 59.375 \\
\cline { 2 - 7 } & SD & 7.42662 & 4.5392 & 1.03013 & 1.01323 & 1.20416 \\
\cline { 2 - 7 } & $\mathrm{N}$ & 16 & 16 & 16 & 16 & 16 \\
\cline { 2 - 7 } & P values & 0.574 & 0.76 & 0.012 & 0.002 & 0.006 \\
\hline \multirow{3}{*}{$>3000$} & MEAN & 44.1783 & 29.8304 & 7.9522 & 7.4 & 58.1739 \\
\cline { 2 - 7 } & SD & 6.03377 & 4.29105 & 1.33446 & 1.26922 & 2.01477 \\
\cline { 2 - 7 } & $\mathrm{N}$ & 23 & 23 & 23 & 23 & 23 \\
\cline { 2 - 7 } & P values & 0.003 & 0.014 & 0 & 0 & 0 \\
\hline \multirow{7}{*}{ **Compared with Control group using Mann Whitney Test } & & \\
\hline
\end{tabular}

Table 3: Mean values of Ivdd, Ivds, pwt, ivst at different ferritin levels (Ng/MI).

\begin{tabular}{|l|c|c|c|c|}
\hline \multicolumn{1}{|c|}{ Variables } & $\begin{array}{c}\text { No. of } \\
\text { patients with } \\
\text { Normal Echo }\end{array}$ & $\begin{array}{c}\text { No. of } \\
\text { patients } \\
\text { cardiac V }\end{array}$ & Total & P value \\
\hline No. of patients with Normal PFT & 23 & 6 & 29 & 0.105 \\
\hline No. of patients with Abnormal PFT & 3 & 15 & 18 & ${ }^{* *} \mathbf{0 . 0 2 0}$ \\
\hline \multicolumn{1}{|c|}{ Total } & 26 & 21 & 47 & \\
\hline${ }^{*}$ Chi square test & \multicolumn{5}{|l}{} \\
\hline${ }^{*}$ Statistically significant
\end{tabular}

Table 4: Correlation between abnormal pft and cardiac pathology in thalassemia major patients.

were female. For comparison of PFT, echocardiography and ferritin level, we had divided the cases in 4 groups: 6-8 years (16 patients), 9-10 years (15 patients), 11-12 years (14 patients) and 13-14 years (2 patients). Controls were also divided into 4 groups: 6-8 years (6), 9-10 years (5), 11-12 years (5) and 13-14 years (4). As per geographical distribution 19 were from rural area and 28 were from urban area. The urban preponderance may be is due to the study center being located in Bhopal itself. Study showed that age was increasing mean serum ferritn level was also increasing and it was statistically significant between 1112 years and $13-14$ years age group ( $p$ value $<0.05$ ). Mean values of $\mathrm{FEV}_{1}$, FVC, decreased suggesting restrictive pattern of PFT while a decrease in FEF $25 \%$ to $75 \%$ also suggested small airway obstruction. The serum ferritin levels increased, mean value of $\mathrm{FEV}_{1}, \mathrm{FVC}, \mathrm{FEV}_{1} / \mathrm{FVC}$ and FEF ( $25 \%$ to $75 \%)$ decreased and it was statistically significant in cases with ferritin $>3000 \mathrm{ng} / \mathrm{ml}$ ( $\mathrm{p}$ value $<0.05$ ). In our study group we observed that, interventricular septal thickness, LV posterior wall thickness, LV dimensions both in systole and diastole was higher in cases as compared to controls. Increase in PWT and IVST were statistically significant ( $p$ 
value 0.000 ). The mean value of $E F$ was lower among cases than it was in controls and this decrease in EF was statistically significant $(\mathrm{p}=0.00)$ but there was no systolic dysfunction as ejection fraction in all patients was $>50 \%$. Mean values of LVDd, LVDs, IVST, and PWT were found to be high in higher ferritin group which were statistically significant $(\mathrm{p}<0.05)$. Ejection fraction was also decreased and was also statistically significant but clinically did not produce systolic dysfunction as EF in all the cases were $>50 \%$. Among 47 Thalassemic patients, 15 were found to have both cardiac pathology as well as pulmonary dysfunction. This finding was statistically significant. Thus, it is advisable to evaluate both the system if either of the system is affected.

\section{Discussion}

We included 47 confirmed cases of thalassemia major in our study; out of which 35 were male and 12 were female. Mean age of thalassemia subjects in our study population was $9.44 \pm 2.030$ years. This was in accordance with the study done by Ozyoruk et al. [6] on 49 thalassemia cases with mean age of $10.83 \pm 3$ years. Hayden et al. also studied 18 thalassemia major children with mean age of 11 years [7].

It was found that as age increases, mean serum ferritin levels also increases and it is due to the increasing burden of transfusion ultimately leading to iron overload as shown by raised serum ferritin. The mean ferritin level in our study was $3217+1351.853$. Different studies have shown wide range of mean Sr. ferritin values. Cunningham et al. in 2004 reported mean serum ferritin level in thalassemia major patients of North America to be $1696 \mathrm{ng} / \mathrm{ml}[8,9]$. However, Choudhry et al. in India reported mean serum ferritin level to be $6723 \mathrm{ng} / \mathrm{ml}$, even higher than in our study [10].

In our study, 18(38\%) patients had low $\mathrm{FEV}_{1}$ and FVC; suggesting restrictive pattern along with small airway obstruction suggested by reduced FEF $25 \%$ to $75 \%$ so these 18 patients showed a mixed pattern of pulmonary impairment. At the same time 9(19\%) patients had reduced FEF $25 \%$ to $75 \%$ only with normal values of other parameters which suggested isolated small airway obstruction. FEF $25 \%$ to $75 \%$ is often said to be a measurement of small airway obstruction. The FEF ( $25 \%$ to $75 \%)$ is fairly non-specific and it can be reduced in many non-obstructive diseases also. Nevertheless, an isolated reduction in the $\mathrm{FEF} 25 \%$ to $75 \%$ serves an important clue to mild obstructive lung disease when the $\mathrm{FEV}_{1} / \mathrm{FVC}$ ratio is normal [11-13].

Our findings are consistent with Gourgollanis et al. who studied forty-two patients of thalassemia major [14]. He observed that $12 \%$ patients had completely normal pulmonary function while $10 \%$ patients had only diffusion impairment. $43 \%$ patients had restrictive and $36 \%$ patients had combined (restrictive and obstructive) pattern of lung disease. Similarly, Alyasin et al. also found that $70 \%$ patients of thalassemia had abnormal result of spirometry. They detected obstructive airway pattern in $8 \%$, restrictive pattern in $12 \%$ and small airway involvement was seen in $50 \%$ cases [15-17].

In our study, we observed that as the serum ferritin level increased, mean value of $\mathrm{FEV}_{1}, \mathrm{FVC}, \mathrm{FEV}_{1} / \mathrm{FVC}$, FEF (25\% to 75\%) decreased and it was statistically significant in cases with ferritin $>3000 \mathrm{ng} / \mathrm{ml}$ (p value $<0.05$ ). In group of 23 patients where Sr. ferritin was $>3000 \mathrm{ng} / \mathrm{dl}$, $15(65 \%)$ cases had low $\mathrm{FEV}_{1}, 13(56 \%)$ cases had low FVC and 17(74\%) cases had low $\operatorname{FEF}(25 \%$ to $75 \%)$ suggesting that Sr. ferritin is a strong predictor for alteration in all the parameters of PFT in thalassemia patients.

Correlation of PFT abnormality and ferritin is a consistent finding with Parakh et al. who showed a significant correlation between serum ferritin with DLCO, FVC and TLC [16]. The presence of iron laden macrophages in BAL indicates that iron plays a major role in the etiopathogenesis of these abnormalities. Similarly Ozyoruk et al. also showed that decreased $\mathrm{FEV}_{1}$ and $\mathrm{FVC}$ were more in patients with ferritin $>2500 \mathrm{ng} / \mathrm{mL}$ than in $<2500 \mathrm{ng} / \mathrm{mL}$ (p=0.04, 0.03) [6].

In our study, when we looked for changes in cardiac parameters, we found that interventricular septal thickness (IVST), posterior wall thickness (PWT), left ventricular diameter both in systole and diastole were higher in cases in comparision to healthy controls. Increase in PWT and IVST were statistically significant $(\mathrm{p}<0.05)$ while increase in ventricular diameter both in systole and diastole were statistically insignificant. Our findings were consistent with Favilli et al. who compared 25 thalassemia major patients (mean age of $15.8 \pm 5.7$ years; with a regular regimen of blood transfusions and chelation therapy) to 25 healthy subjects [18]. The mean value of LVDd and left ventriclular MI was significantly increased in cases as compared to controls. Similar findings were also reported in other studies like Sayed et al. who showed significant increase in LVDd, LVDs, PWT, IVST in cases as compared to controls ( $\mathrm{p}$ value $<0.05)$ [19].

The mean value of EF was lower among cases than in controls and this decrease in EF was statistically significant $(\mathrm{p}<0.05)$ but there was no systolic dysfunction as Ejection fraction in all patient was $>50 \%$.

Mean values of left ventricular diameter in systole and diastole, inerventricular septal thickness and posterior wall thickness were high in higher ferritin group. Ejection fraction was also decreased but clinically did not produce systolic dysfunction as $\mathrm{EF}>50 \%$.

16 patients out of 23(69\%) had dilated cardiomypathy in group where sr ferritin was $>3000 \mathrm{ng} / \mathrm{dl}$ and 5 patients out of $17(31 \%)$ had dilated cardiomypathy in ferritin levels of 2000-3000 ng/dl and no cardiomyopathy was found in yet lower ferritin range group i.e. in group with Sr. ferritin 1000-2000 ng/dl. Our finding are consistent with study done by Lai et al. who found that $49 \%$ of the thalassemic patients of their study population had cardiac disease, so they concluded that the risk of cardiac complication was increased to 10 -fold with increase in Sr. ferritin levels [20].

In our study among 47 Thalassemic patients, 23 thalassemics patients had normal PFT and Echocardiography. 6 patients had cardiac pathology with normal PFT and 3 patients had abnormal PFT with normal echocardiography. 15 (40\%) were found to have both cardiac pathology as well as pulmonary dysfunction. Thus, it is advisable to evaluate both the system if either of the system is affected. Studies are needed to establish this relationship.

\section{Conclusions}

There is mixed pattern of respiratory impairment in thalassemia patients (both obstructive and restrictive). All the PFT parameters were decreased with increasing Sr. ferritin level. Nearly half of the patients were found to have both pulmonary and cardiac involvement so it is advisable to look for both the systems if either of the system is affected. Therefore regular, uninterrupted and judicious chelation therapy shall be given with meticulous monitoring of serum ferritin levels so that the cardiopulmponary complication can be prevented in the thalassemic patient.

\section{References}

1. Modell B, Darlison M (2008) Global epidemiology of haemoglobin disorders and derived service indicators. Bull World Health Organ 86: 480-487.

2. Madan N, Sharma S, Rusia U, Sen S, Sood SK (1998) Beta thalassemia mutation in Northern India (Delhi). Ind J Med Res 107: 134-141.

3. Olivieri NF, Nathan DG, MacMillan JH, Wayne AS, Liu PP, et al. (1994) Survival 
Citation: Nandurkar P, Goel M, Sharma S (2018) A Study on Cardiopulmonary Function Tests in Thalassemia Major Patients (6-14 Years) and its Correlation to Serum Ferritin. J Pulm Respir Med 8: 450. doi: 10.4172/2161-105X.1000450

Page 4 of 4

in medically treated patients with homozygous beta-thalassemia. N Eng J Med 331: 574-578.

4. Leonardi B, Margossian R, Colan SD, Powell AJ (2008) Relationship of magnetic resonance imaging estimation of myocardial iron to left ventricular systolic and diastolic function in thalassemia. JACC Cardiovasc Imaging 1: $572-578$

5. Quanjer PH, Stanojevic S, Cole TJ, Baur X, Hall GL, et al. (2012) Multi-ethnic reference values for spirometry for the 3-95 year age range: The global lung function 2012 equations Report of the global lung function initiative (GLI), ers task force to establish improved lung function reference values Eur Respir $\mathrm{J}$ 40: $1324-1343$

6. Ozyoruk D, Misirlioglu ED (2015) Pulmonary functions in children with thalassemia major. J Pediatr Hematol Oncol 37: 605-610.

7. Hayden LP, Berkovits D, Kleiner D, Needleman (2013) Pulmonary function testing abnormalities among children with thalassemia major. Am J respire crit care med 187: A1789.

8. Arora M, Chandra J, Suri JC, Narayana S, Dutta AK (2001) Pulmonary function test in beta thalassemia. IJP 68: 239-242.

9. Cunningham MJ, Macklin EA, Neufeld EJ, Cohen AR, Thalassemia Clinical Research Network (2004) Complications of beta-thalassemia major in North America. Blood 104: 34-39.

10. Choudhry VP, Pati HP, Saxena A, Malaviya AN (2004) Deferiprone, efficacy and safety. Indian J Pediatr 71: 213-216.

11. Grisaru D, Rachmilewitz EA, Mosseri M, Gotsman M, Okon E, et al. (1990) Cardiopulmonary assessment in beta-thalassemia major. Chest 98: 1138-1142.
12. Bacalo A, Kivity S, Heno N, Greif Z, Greif J, et al. (1992) Blood transfusion and lung function in children with thalassemia major. Chest 101: 362-365.

13. Piatti G, Allegra L, Ambrosetti U, Cappellini MD (1999) Lung function in beta thalassemia. Hematologica 84: 804-808

14. Kanj N, Ali S, Walid G, Kanj M, Nasr A, et al. (2000) Relation of ferritin levels to pulmonary function in patients with thalassemia major and the acute effects of transfusion. Eur J Hematol 64: 396-400.

15. Li AM, Chan D, Li CK, Wong E, Chan YC, et al. (2002) Respiratory function in patients with thalassaemia major: relation with iron overload. Arch Dis Child 87: 328-330.

16. Parakh A, Dubey, AP, Chowdhury V, Sethi GR, Jain S, et al. (2007) Study of pulmonary function tests in thalassemic children. J Pediatr Hematol Oncol 29 151-155.

17. Alyasin S, Moghtaderi M, Amin R, Kashef S, Karimi M (2011)pulmonary function test in transfusion-dependent $\beta$-thalassemia major patients: A pilot study, Pediatr Hematol Oncol 28: 329-333.

18. Favilli S, DeSimone L, Mori F, Pollini I, Cecchi F, et al. (1993) The cardiac changes in thalassemia major: Their assessment by Doppler echocardiography. G Ital Cardiol 23: 1195-2000.

19. Hyder SN, Kazmi U, Malik A (2013) An echocardiographic evaluation of left ventricular function in patients with thalassemia major. J Pak Med Stud 3: 10-15.

20. Olson LJ, Edwards WD, McCall JT, Ilstrup DM, Gersh BJ (1987) Cardiac iron deposition in idiopathic hemochromatosis. J Am Coll Cardiology 10: 1239-1243. 